\title{
Desempenho agroeconômico da cenoura adubada com jitirana (Merremia aegyptia)
}

\author{
Mychelle Karla T de Oliveira ${ }^{1}$; Francisco Bezerra Neto ${ }^{1}$; Aurélio P Barros Júnior ${ }^{2}$; Joserlan N Moreira ${ }^{1}$; \\ José Roberto de Sá1; Paulo César F Linhares ${ }^{1}$ \\ 1UFERSA, C. Postal 137, 59625-900 Mossoró-RN; mkto10@hotmail.com; bezerra@ufersa.edu.br; moreiragronomo@hotmail.com; \\ sajrobert@yahoo.com.br; paulolinhares@ufersa.edu.br; ${ }^{2}$ UFRPE, R Dom Manoel de Medeiros s/n, Dois Irmãos, 52171-900 Recife-PE; \\ aureliojr02@yahoo.com.br
}

\section{RESUMO}

O uso de plantas espontâneas do bioma Caatinga como adubo verde vem se constituindo numa opção viável de produção de hortaliças na região do Nordeste brasileiro. Entre essas plantas, está a jitirana, planta espontânea adaptada às condições edafoclimáticas da região, com alta produção de fitomassa, rápido crescimento e estreita relação $\mathrm{C}: \mathrm{N}$. O objetivo desse trabalho foi avaliar o desempenho agroeconômico da cenoura (cv. Brasília) em função de quantidades de jitirana adicionadas sob o solo e de seus tempos de incorporação. O estudo foi conduzido em área rural, localizada em Mossoró (RN), de setembro a dezembro de 2009. O delineamento experimental usado foi em blocos completos casualizados com os tratamentos arranjados em esquema fatorial $(4 \mathrm{x} 4)+1$, com 3 repetições. O primeiro fator foi constituído pelas quantidades de jitirana colocadas entre as linhas de cenoura até a profundidade de $15 \mathrm{~cm}\left(5,4 ; 8,8 ; 12,2\right.$ e $15,6 \mathrm{t} \mathrm{ha}^{-1}$ em base seca) e o segundo fator pelos tempos de incorporação desse material $(0,15,30$ e 45 dias depois da semeadura da cenoura). $\mathrm{O}$ tratamento adicional (testemunha) foi de $40 \mathrm{tha}^{-1}$ de esterco bovino aplicado 10 dias antes da semeadura. Foram avaliados a produtividade comercial e total de raízes, percentagens das diversas classes de raízes e os indicadores econômicos, renda bruta, renda líquida, taxa de retorno e índice de lucratividade. Não houve interação significativa entre os fatores quantidades de jitirana sob o solo e seus tempos de incorporação em nenhuma das características avaliadas na cenoura. O melhor desempenho agroeconômico do cultivo da cenoura foi obtido com a adição ao solo de $15,6 \mathrm{t} \mathrm{ha}^{-1}$ de jitirana. A otimização desse desempenho foi alcançada no tempo de incorporação de 26 dias.

Palavras-chave: Daucus carota, adubo verde, eficiência agronômica.

\section{ABSTRACT \\ Agroeconomic performance of carrot fertilized with scarlet starglory (Merremia aegyptia)}

The use of spontaneous plants of the Caatinga biome as green manure is becoming a viable option for vegetable production in northeastern Brazil. Among these plants, the scarlet starglory is a spontaneous plant adapted to the climatic and soil conditions of the region, with high biomass production, rapid growth and low $\mathrm{C} / \mathrm{N}$ ratio. We evaluated the agroeconomic performance of carrot (cv. Brasília) depending on added amounts of scarlet starglory under the ground and of its moment of incorporation. The study was carried out in a rural area, in Mossoró, Rio Grande do Norte state, Brazil, from September to December 2009. The experimental design was randomized complete blocks with the treatments arranged in a factorial scheme $(4 \mathrm{x} 4)+1$, with three replications. The first factor was comprised of amounts of scarlet starglory placed between the carrot rows, in a depth of $15 \mathrm{~cm}\left(5.4,8.8,12.2\right.$ and $15.6 \mathrm{tha}^{-1}$ on a dry basis) and the second factor, of the incorporation moment of this material $(0,15,30$ and 45 days after sowing carrots). The additional treatment (control) was $40 \mathrm{t} \mathrm{ha}^{-1}$ of cattle manure applied 10 days before sowing. We evaluated the marketable and total yield of roots, percentage of the different classes of roots and the economic indicators of gross income, net income, rate of return and profit margin. No significant interaction between the amounts of scarlet starglory under the soil and the incorporation moment was determined in any of the characteristics examined for carrot. The best agroeconomic performance of carrot cropping was obtained by adding $15.6 \mathrm{t} \mathrm{ha}^{-1}$ of scarlet starglory to the soil. The optimization of this performance was achieved with the incorporation moment of 26 days after carrot sowing.

Keywords: Daucus carota, green manure, agronomic efficiency.

\section{(Recebido para publicação em 7 de junho de 2011; aceito em 15 de julho de 2012) (Received on June 7, 2011; accepted on July 15, 2012)}

$\mathrm{O}$ cultivo da cenoura no Nordeste brasileiro tem sido realizado em sua maioria com adubação mineral e orgânica, principalmente com o uso de esterco bovino, insumo não tão barato e nem de fácil aquisição, acarretando às vezes, em elevados custos de produção (Oliveira et al., 2011). Uma das estratégias que vem sendo usada para mudar este paradigma, é a utilização de espécies espontâneas do bioma Caatin- ga como adubo verde, constituindo-se numa opção importante de produção agrícola para alcançar o equilíbrio entre o aumento da produtividade das culturas e a exploração do meio ambiente.

Essas espécies, além de serem adaptadas às condições edafoclimáticas da região, apresentam alta produção de fitomassa, rápido crescimento, estreita relação C:N (Linhares et al., 2012) e vantagens como o menor custo de obtenção e poderem ser coletadas nas proximidades de propriedades rurais. $\mathrm{Na}$ prática da adubação verde, elas têm sido usadas para o suprimento mineral das plantas, ciclagem rápida de nutrientes, intensificação da atividade biológica do solo, aumento dos teores de nitrogênio disponíveis para as plantas, controle de pragas, doenças e plantas invasoras, aumento da capacidade de armazenamento de água, diminuição da temperatura, 
descompactação e aumento do nível de matéria orgânica do solo (Bezerra Neto et al., 2011; Góes et al., 2011).

Entre essas espécies está a jitirana, planta espontânea da família convolvulácea, forrageira, nativa do Nordeste brasileiro, suculenta e com odor agradável, muito comum durante o período chuvoso. Encontra-se em matas, cercas, clareiras e roçados, adaptando-se a solos de diferentes composições granulométricas (Braga, 1976; Correia, 1984). É uma trepadeira anual, herbácea, com caule cilíndrico, sulcado, glabro, ou, mais comumente, com pubescência hirsuta, amarelada, com folhas alternadas, membranáceas, com cinco segmentos, palmadas, face ventral e dorsal esparsamente pilosa, inflorescências com 6 a 9 flores raramente solitárias, flores alvas, cálice densamente piloso e corola campanulada, externamente glabra, fruto cápsula subglobosa (Barbosa, 1997).

Trabalhos têm evidenciado efeito positivo da jitirana na produtividade ou rendimento das culturas, como aumento de rendimento de massa verde de rúcula (Linhares et al., 2007), de alface (Góes et al., 2011; Bezerra Neto et al., 2011) e de coentro (Linhares, 2009) com a incorporação de jitirana (Merremia aegyptia) ao solo, aumento no rendimento de massa verde de rúcula com a incorporação de mata pasto (Senna uniflora) e aumento na massa verde de coentro com a incorporação de flor-de-seda (Calotropis procera) (Linhares, 2009). Em hortaliças tuberosas, também constam resultados de aumentos na produtividade de raízes comerciáveis de beterraba (Silva et al., 2011) e de rabanete (Batista, 2011) com a incorporação de jitirana.

A fim de fornecer maiores subsídios para o uso da jitirana como adubo verde em sistemas de cultivos com tuberosas, propõe-se com este trabalho, avaliar o desempenho agroeconômico da cenoura em função de quantidades de jitirana adicionadas sob o solo e de seus tempos de incorporação.

\section{MATERIAL E MÉTODOS}

$\mathrm{O}$ experimento foi conduzido em área de produtor, em Mossoró (RN)
(5'03'37'S 37²3'50"'W, altitude de 72 $\mathrm{m})$, de setembro a dezembro de 2009 , em solo classificado como Latossolo Vermelho Amarelo Argissólico franco arenoso (Embrapa, 2006). Segundo a classificação de Thornthwaite, o clima local é DdAa', ou seja, semi-árido, megatérmico e com pequeno ou nenhum excesso d'água durante o ano, e de acordo com Köppen é BSwh', seco e muito quente, com duas estações climáticas: uma seca, que geralmente compreende o período de junho a janeiro e uma chuvosa, entre os meses de fevereiro e maio (Carmo Filho et al., 1991). Durante o período desta pesquisa, a temperatura média diária foi $27,4^{\circ} \mathrm{C}$, radiação global 20,4 $\mathrm{mj} \mathrm{m}^{-2}$ dia $^{-1}$, umidade relativa $63,5 \%$ e precipitação pluviométrica de $1,3 \mathrm{~mm}$.

A análise do solo na profundidade de 0-20 cm, antes da instalação do experimento, proporcionou os seguintes resultados: $\mathrm{pH}$ (água $1: 2,5)=6,0 ; \mathrm{Ca}=$ $2,0 \mathrm{cmol}_{\mathrm{c}} \mathrm{dm}^{-3} ; \mathrm{Mg}=0,5 \mathrm{cmol}_{\mathrm{c}} \mathrm{dm}^{-3} ; \mathrm{K}=$ $0,12 \mathrm{cmol}_{\mathrm{c}} \mathrm{dm}^{-3} ; \mathrm{Na}=0,20 \mathrm{cmol}_{\mathrm{c}} \mathrm{dm}^{-3}$; $\mathrm{P}=27,7 \mathrm{mg} \mathrm{dm}^{-3} ;(\mathrm{H}+\mathrm{Al})=0,66 \mathrm{cmol}^{\circ}$ $\mathrm{dm}^{-3} ; \mathrm{Al}=0,00 \mathrm{cmol}_{\mathrm{c}} \mathrm{dm}^{-3} ; \mathrm{V} \%=89,85$ e $\mathrm{CE}=1,77 \mathrm{dS} \mathrm{m}{ }^{-1}$ e M.O.= 3,6 $\mathrm{g} \mathrm{kg}^{-1}$; $70,6 \%$ areia; $12,4 \%$ silte e $17,0 \%$ argila.

$\mathrm{O}$ delineamento experimental utilizado foi em blocos completos casualizados com os tratamentos arranjados em esquema fatorial $(4 \mathrm{x} 4)+1$, com 3 repetições. Os tratamentos consistiram da combinação de quatro quantidades de jitirana colocadas entre as linhas de cenoura até a profundidade de $15 \mathrm{~cm}(5,4$; 8,$8 ; 12,2$ e 15,6 t ha $^{-1}$ em base seca), com quatro tempos de incorporação desse material: $0,15,30$ e 45 dias depois da semeadura da cenoura (DDS), além de um tratamento testemunha com $40 \mathrm{tha}^{-1}$ de esterco bovino aplicado e misturado ao solo 10 dias antes do plantio, segundo utilização tradicional no cultivo desta hortaliça (Paula Júnior \& Venzon, 2007; UFC, 1993). Cada parcela teve uma área total de $1,44 \mathrm{~m}^{2}(1,20 \mathrm{~m} \times 1,20 \mathrm{~m})$, com seis fileiras e uma área útil de $0,80 \mathrm{~m}^{2}$ $(0,80 \mathrm{~m} 1,00 \mathrm{~m})$, formada pelas quatro fileiras centrais com 10 plantas cada. As fileiras ou linhas de plantio foram dispostas transversalmente no canteiro, espaçadas entre si de 0,20 m e dentro da linha nos espaçamentos de $0,10 \mathrm{~m}$, resultando uma população teórica de 500.000 plantas ha ${ }^{-1}$, sem levar em consideração os $30 \%$ de área de transito, composta de corredores e estradas. Mas, para a quantificação das características produtividade comercial e total e percentagem classificada de raízes e dos indicadores econômicos foram feitas as correções para $70 \%$ da área plantada.

O preparo do solo consistiu de uma gradagem seguida do levantamento dos canteiros, realizado manualmente com auxilio de enxadas. Após a construção dos canteiros foi realizada uma solarização durante 30 dias com a finalidade de reduzir a população de nematóides das galhas.

A jitirana foi coletada nas proximidades do Campus da UFERSA, em plena floração, dando-se preferência aos locais onde a planta se desenvolveu sobre plantas arbóreas, sobre cercas ou onde se verificava elevada predominância da jitirana, com o objetivo de evitar a contaminação do material com outras espécies. A jitirana coletada foi triturada em uma picadeira, e em seguida posta para secar em uma área cimentada, até atingir teor de $10 \%$ de umidade, com intuito de que as quantidades fossem estimadas em base de matéria seca. Foram retiradas amostras de jitirana seca, levadas ao laboratório da UFERSA para análise no tecido vegetal dos teores de nitrogênio, fósforo, potássio, cálcio, magnésio e relação carbono/nitrogênio, cujos resultados foram 21,$4 ; 6,79 ; 10,0$; 12,0 e $18,0 \mathrm{~g} \mathrm{~kg}^{-1}$ e 18/1, respectivamente.

O plantio foi realizado em 02/09/09 em semeadura direta, aproximadamente $2 \mathrm{~cm}$ de profundidade, com três a cinco sementes por cova. Aos 23 dias após a semeadura foi realizado o desbaste, deixando-se uma planta por cova.

As irrigações foram efetuadas por micro-aspersão, com turno de rega diária parcelada em duas aplicações (manhã e tarde), fornecendo-se uma lâmina de água de aproximadamente $8 \mathrm{~mm} \mathrm{dia}^{-1}$. Foram realizadas ainda duas capinas manuais.

A colheita foi realizada aos 95 dias após a semeadura (06/12/09). Logo após a colheita, as raízes foram transportadas para o laboratório da UFERSA, onde foram analisadas. 
Foram avaliadas as características de produção (produtividade comercial e total de raízes e percentagem classificada de raízes longas, médias e curtas), além dos indicadores econômicos (renda bruta, renda líquida, taxa de retorno e índice de lucratividade).

As produtividades comercial e total foram quantificadas a partir da massa fresca das 40 raízes da área útil da parcela, expressas em t ha ${ }^{-1}$. Considerou-se como produtividade total todas as raízes da área útil e para produtividade comercial as raízes livres de rachaduras, bifurcações, galhas de nematóides e danos mecânicos. A percentagem de raízes em cada classe foi obtida de acordo com o comprimento e maior diâmetro transversal, classificando-as como longas (17-25 cm de comprimento e diâmetro menor que $5 \mathrm{~cm}$ ), médias (comprimento de $12-17 \mathrm{~cm}$ e diâmetro maior que 2,5 $\mathrm{cm}$ ), curtas (comprimento de $5-12 \mathrm{~cm}$ e diâmetro maior que $1 \mathrm{~cm}$ ), conforme
Lana \& Vieira, (2000).

Análises de variância das características avaliadas, depois de feitas as correções para $70 \%$ da área plantada, onde fora retirada a área de transito, composta de corredores e estradas, foram realizadas com o auxílio do aplicativo software SISVAR 3.01 (Ferreira, 2000). O procedimento de ajustamento de curva de resposta foi feito através do software Table Curve (SYSTAT SOFTWARE INC., 2002), tanto nas características de produção como nos indicadores econômicos em função das quantidades de jitirana e dos tempos de incorporação.

\section{RESULTADOS E DISCUSSÃO}

Não foi observada interação significativa entre as quantidades de jitirana adicionadas ao solo e seus tempos de incorporação nas características avaliadas da cenoura. A produtividade comercial máxima $\left(20,64 \mathrm{t} \mathrm{ha}^{-1}\right)$ foi obtida com a incorporação de 15,6 t ha-1 de jitirana, correspondendo a um incremento de $28,5 \%$ em relação à menor quantidade de jitirana aplicada $\left(5,4 \mathrm{t} \mathrm{ha}^{-1}\right)$ (Figura 1A). A resposta ascendente na produtividade comercial em função do aumento de aplicação de jitirana pode ser atribuída ao maior suprimento nutricional das plantas de cenoura, adequada sincronia entre a decomposição e mineralização da jitirana adicionada e a época de maior exigência nutricional da cultura (Fontanétti et al., 2006).

Essa produtividade comercial máxima de cenoura adubada com jitirana de 20,64 $\mathrm{t} \mathrm{ha}^{-1}$ obtida foi superior a obtida por Oliveira et al. (2001), trabalhando com a mesma cultivar desta pesquisa nas condições de Areia (PB) adubada com húmus de minhoca $\left(15,5 \mathrm{t} \mathrm{ha}^{-1}\right)$, e um pouco inferior, a obtida com adubação mineral $\left(25,5 \mathrm{t} \mathrm{ha}^{-1}\right)$. A resposta positiva da adubação com jitirana evidencia a

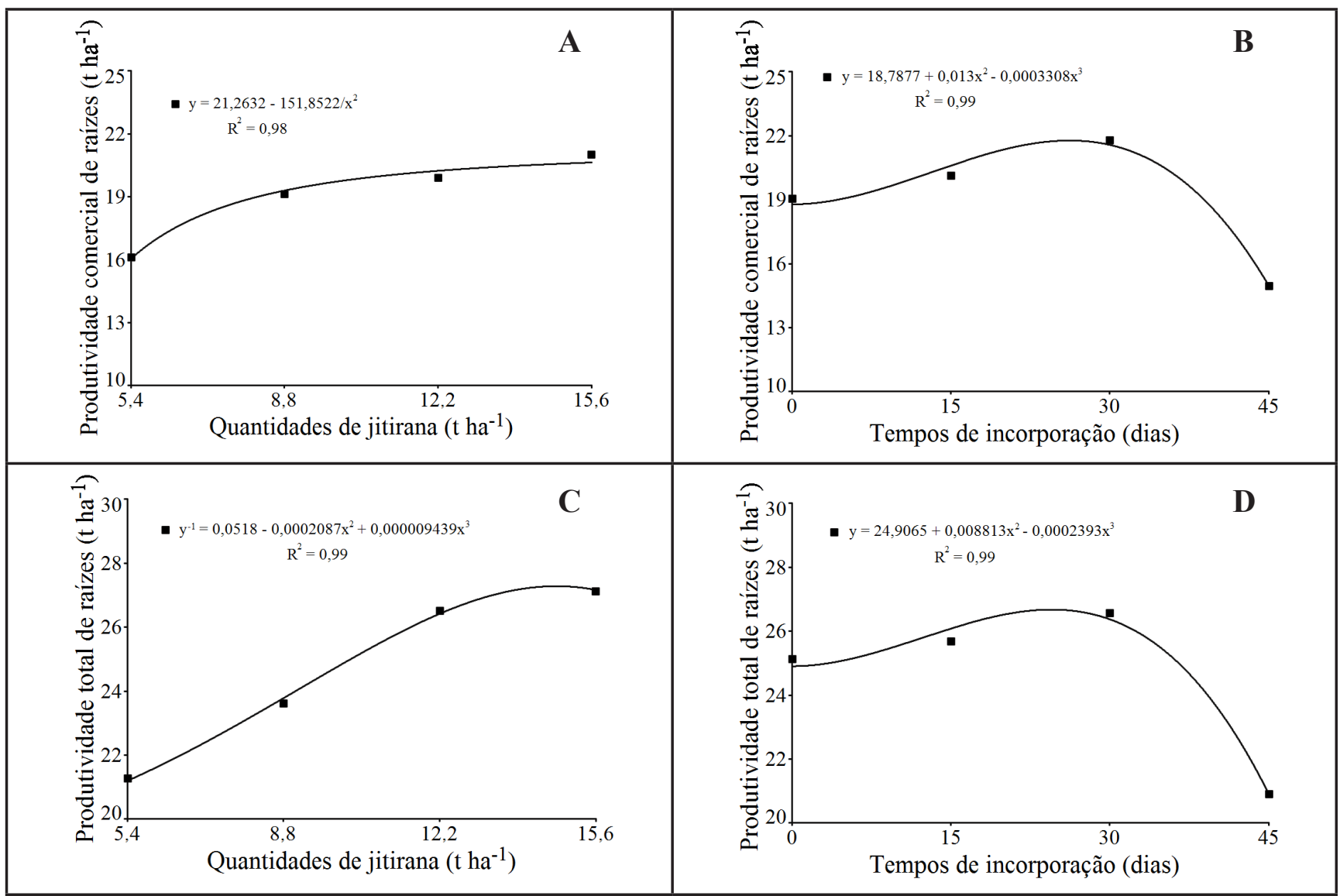

Figura 1. Produtividade comercial e total de raízes de cenoura em função de quantidades de jitirana adicionadas sob o solo (A e C) e de seus tempos de incorporação (B e D) [marketable and total yield of carrot roots depending on the amount of scarlet starglory added to the soil (A and C) and of the incorporation moment (B and D)]. Mossoró, UFERSA, 2009. 


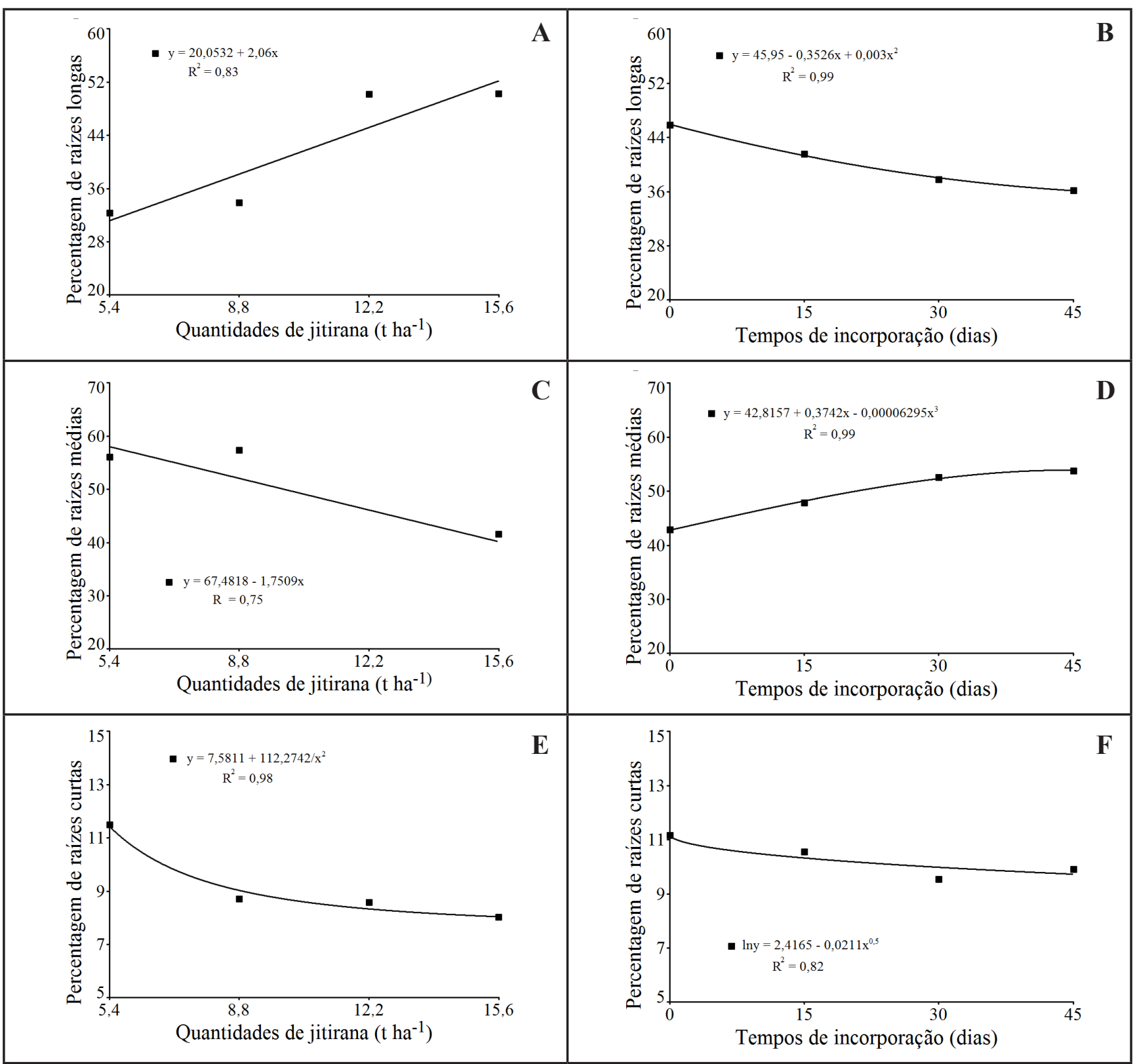

Figura 2. Raízes longas, médias e curtas (\%) de cenoura em função de quantidades de jitirana adicionadas sob o solo (A, C e E) e de seus tempos de incorporação (B, D e F) [long, intermediate and short roots (\%) of carrot depending on the amount of scarlet starglory added to the soil (A, C and E) and of its incorporation moment (B, D and F)]. Mossoró, UFERSA, 2009.

potencialidade desta espécie para ser utilizada como adubo verde.

Em relação aos tempos de incorporação, essa produtividade comercial de raízes aumentou até os 26 dias depois da semeadura da cenoura, atingindo o valor máximo de 21,78 tha ${ }^{-1}$, correspondendo ao acréscimo de 15,9\% em relação ao tempo zero, decrescendo, em seguida, até o fornecimento de jitirana aos 45 dias depois da semeadura (Figura 1B). O tempo de 28 dias obtidos por Linhares et al. (2009), proveniente do efeito de tempos de decomposição da jitirana na produtividade do rabanete, diverge do estimado nesse trabalho (26 dias), podendo essa diferença ser atribuída ao menor ciclo da cultura do rabanete (em torno de 30 dias). Considerando que a mineralização e posterior liberação de nutrientes ocorre em torno de 40 dias depois da incorporação, pode ter ocorrido uma sincronia entre a disponibilidade de nutrientes oriundos da adição da jitirana e a fase de maior exigência nutricional do rabanete (Torres et al., 2005).

Houve um incremento na produtividade total de raízes de cenoura com as quantidades crescentes de jitirana sob o solo até o valor máximo de $27,28 \mathrm{t}$ ha $^{-1}$ na quantidade de jitirana de 14,74 t ha ${ }^{-1}$, decrescendo, em seguida, até a última quantidade de jitirana adicionada e também dessa produtividade com os tempos de incorporação desse material até o valor máximo de $26,68 \mathrm{t} \mathrm{ha}^{-1}$ no tempo de 25 dias de incorporado, decrescendo, até o seu fornecimento aos 45 dias depois da semeadura da cenoura (Figuras 1C e 1D). Essa otimização, se deve, em parte, à maior disponibilidade de nutrientes liberados pela jitirana, 


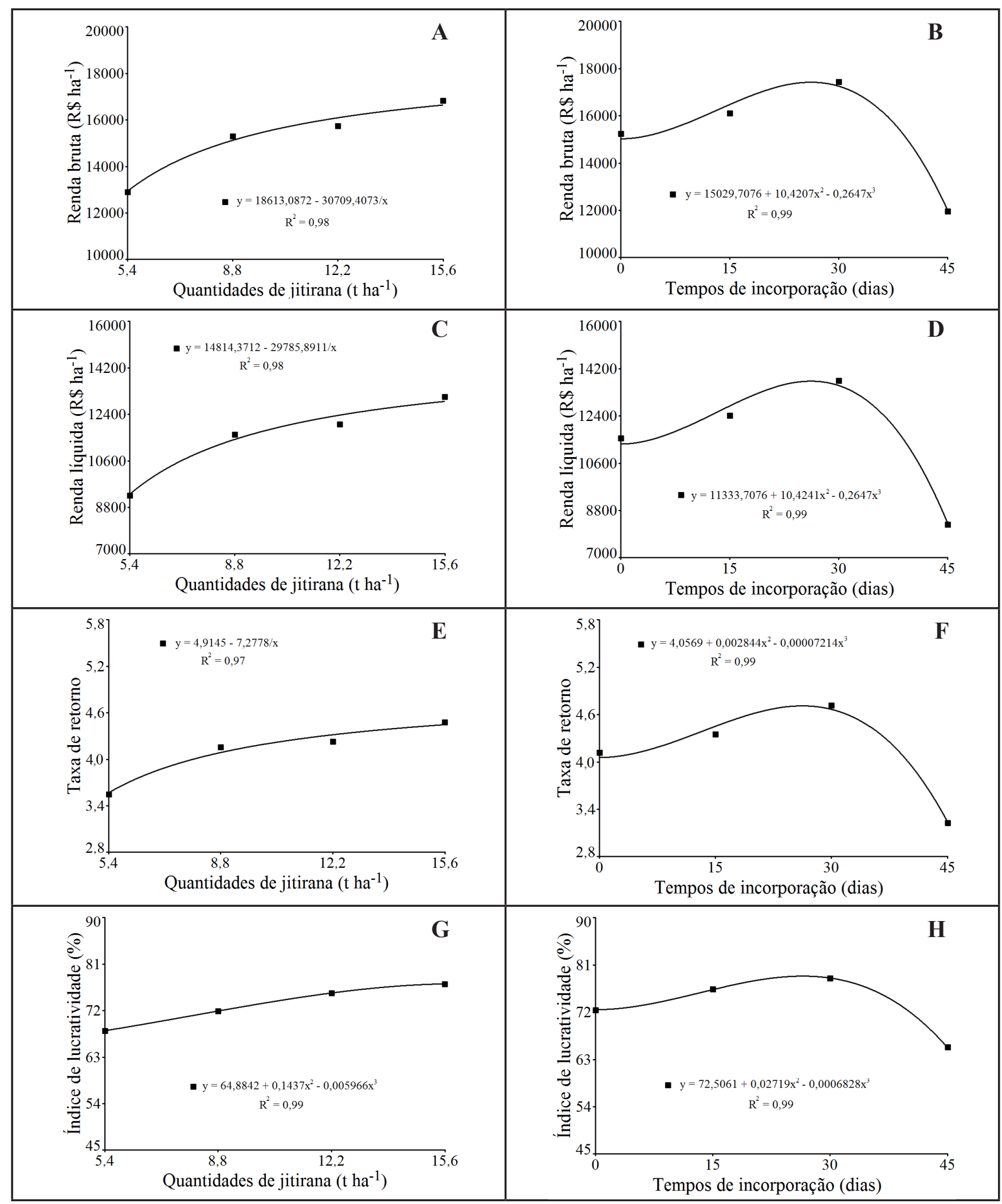

Figura 3. Renda bruta e liquida, taxa de retorno e índice de lucratividade de cenoura em função de quantidades de jitirana adicionadas sob o solo (A, C e E) e de seus tempos de incorporação (B, D e F) [gross and net income, rate of return and profit margin of carrot depending on the amount of scarlet starglory added to the soil (A, C, E and G) and on the incorporation moment (B, D, F and H)]. Mossoró, UFERSA, 2009. 
Tabela 1. Valores médios da testemunha e dos tratamentos provenientes do fatorial na produtividade comercial (PCR) e total de raízes (PTR), percentagens de raízes longas (PRL), médias (PRM) e curtas (PRC), renda bruta (RB), renda líquida (RL), taxa de retorno (TR) e índice de lucratividade (IL) de cenoura em função de quantidades de jitirana adicionadas ao solo e de seus tempos de incorporação (mean values of the control and treatments from the factorial scheme in the productivity of marketable (PCR) and total roots (PTR), percentages of long (PLR), mean (PMR) and short roots (PSR), gross income (GI), net income (NI), rate of return (RR) and profit margin (PM) of carrot depending on the amount of scarlet starglory added to the soil and on the incorporation moment). Mossoró, UFERSA, 2009.

\begin{tabular}{|c|c|c|c|c|c|c|c|c|c|}
\hline Tratamentos & $\begin{array}{l}\text { PCR } \\
\left(\mathrm{t} \mathrm{ha}^{-1}\right)\end{array}$ & $\begin{array}{c}\text { PTR } \\
\left(\mathrm{t} \mathrm{ha}^{-1}\right)\end{array}$ & $\begin{array}{l}\text { PRL } \\
(\%)\end{array}$ & $\begin{array}{c}\text { PRM } \\
(\%)\end{array}$ & $\begin{array}{l}\text { PRC } \\
(\%)\end{array}$ & $\begin{array}{c}\mathbf{R B} \\
\left(\mathbf{R} \$ \mathbf{h a}^{-1}\right)\end{array}$ & $\begin{array}{c}\text { RL } \\
\left(\mathbf{R} \$ \mathbf{h a}^{-1}\right)\end{array}$ & TR & $\begin{array}{l}\text { IL } \\
(\%)\end{array}$ \\
\hline Testemunha $^{1}$ & $25,9 \mathrm{a}$ & $31,5 \mathrm{a}$ & $37,5 \mathrm{a}$ & $49,0 \mathrm{a}$ & $13,5 \mathrm{a}$ & $20.731,66 \mathrm{a}$ & $13.175,67 \mathrm{a}$ & $2,74 \mathrm{~b}$ & $63,23 \mathrm{a}$ \\
\hline Fatorial & $19,0 \mathrm{~b}$ & $24,5 \mathrm{~b}$ & $30,1 \mathrm{a}$ & $52,5 \mathrm{a}$ & $17,4 \mathrm{a}$ & $15.197,44 \mathrm{~b}$ & $11.501,44 \mathrm{a}$ & $4,11 \mathrm{a}$ & $73,18 \mathrm{a}$ \\
\hline
\end{tabular}

* Médias da testemunha significativamente diferente da média dos tratamentos provenientes do fatorial pelo teste Dunnett, ao nível de 5\% de probabilidade (average values from control treatment differed from the average values of the treatments obtained from the factorial, Dunnett, $5 \%$ ); ${ }^{1}$ Testemunha esterco bovino (control using cattle manure).

como também, pela sincronia na qual esses elementos são liberados e absorvidos pela planta. A taxa de decomposição de resíduos orgânicos está ligada à relação carbono:nitrogênio $(\mathrm{C}: \mathrm{N})$ do material sob esse processo, que no caso da jitirana foi de 18:1. Com a adição de resíduos com relação $\mathrm{C}: \mathrm{N}$ entre $18: 1 \mathrm{e}$ 30:1, não há nem predomínio de imobilização nem mineralização de N. Além dessa disponibilização de nutrientes fornecida pelas quantidades crescentes de jitirana, esse resultado também se deve à influencia que os adubos verdes exercem sobre as propriedades físicas, químicas e biológicas do solo, uma vez que eles apresentam efeitos condicionadores e aumentam a capacidade do solo em armazenar nutrientes necessários ao desenvolvimento das plantas, resultando em maior produtividade de raízes.

Foi registrado um aumento de $21,0 \%$ na quantidade de raízes longas com aplicação de quantidades crescentes de jitirana e, aumento de $11,1 \%$ na quantidade de raízes médias com o aumento nos tempos de incorporação (Figuras 2A e 2D). Por outro lado, decréscimos foram observados nas quantidades de raízes médias $(17,8 \%)$ e curtas $(3,4 \%)$ em função das quantidades de jitirana adicionadas e, decréscimo nas quantidades de raízes longas $(9,8 \%)$ e curtas $(1,5 \%)$ sob os tempos de incorporação do material (Figuras 2C, 2E, 2B e 2F). $A$ adição de matéria orgânica ao solo favorece o desenvolvimento de raízes das plantas. As quantidades de raízes longas, médias e curtas obtidas variaram de 32,4-50,3\%; de 41,2-57,4\% e $8,03-11,5 \%$ respectivamente, em função das quantidades de jitirana aplicadas.
Sabe-se que a temperatura é um dos fatores climático de maior importância que estimulam a formação de raízes e também que existem cultivares que formam boas raízes (longas e médias) sob temperaturas de 18 a $28^{\circ} \mathrm{C}$ (Paula Júnior \& Venzon, 2007). A temperatura média diária durante o período experimental dessa pesquisa foi a redor de $27,4^{\circ} \mathrm{C}$, um pouco abaixo do limite da faixa mencionada, e plantada a cultivar Brasília, recomendada para condições de temperaturas elevadas e dias longos.

Os indicadores econômicos de renda bruta (RB), renda líquida (RL), taxa de retorno (TR) e índice de lucratividade (IL) máximos (R $\$ 25667,47$; $\$$ 12974,64; 1,97 e 49,40\%) foram obtidos na quantidade de jitirana de $15,6 \mathrm{tha}^{-1}$, correspondendo a um incremento de $28,7 \%, 38,8 \%, 24,6 \%$ e $9,1 \%$ ) em relação ao da menor quantidade de jitirana $\left(5,4 \mathrm{t} \mathrm{ha}^{-1}\right)$ (Figuras 3A, 3C, 3E e 3G). Esses resultados se devem ao fato de que a cenoura respondeu muito bem à adubação verde, e que esses indicadores econômicos promissores advieram do melhor aproveitamento dos recursos ambientais pelas plantas de cenoura proporcionadas pelas quantidades de jitirana testadas. Assim, a eficiência agronômica do desempenho produtivo da cenoura foi traduzida em eficiência econômica.

Em relação aos tempos de incorporação, esses indicadores econômicos aumentaram até os 26 dias depois da semeadura da cenoura, atingindo os valores máximos de $\mathrm{RB}=\mathrm{R} \$ 17.424,14$ $\mathrm{ha}^{-1} ; \mathrm{RL}=\mathrm{R} \$ 13.728,14 \mathrm{ha}^{-1} ; \mathrm{TR}=4,71$; $\mathrm{IL}=78,89 \%$ correspondendo aos acréscimos de: $41,0 \% ; 65,5 \% ; 45,4 \%$ e $13,5 \%$ em relação ao tempo zero, decrescendo, em seguida, até o fornecimento de jitirana aos 45 dias depois da semeadura (Figuras 3B, 3D, 3F e 3H). Diante disso, observa-se, que a otimização do desempenho econômico da cenoura foi obtida no tempo de incorporação da jitirana aos 26 dias, ditada pela renda líquida, que é um dos indicadores que expressa melhor o valor econômico dos sistemas de cultivos, do que a renda bruta, porque nela se encontram deduzidos os custos de produção (Bezerra Neto et al., 2012).

Para a produtividade comercial e total de raízes e renda bruta da cenoura foram observadas diferenças significativas entre as médias da testemunha e dos tratamentos provenientes do fatorial, com as maiores médias registradas na testemunha $\left(25,9 \mathrm{t} \mathrm{ha}^{-1}, 31,5 \mathrm{tha}^{-1} \mathrm{e} \mathrm{R} \$\right.$ $20.731,66 \mathrm{ha}^{-1}$, respectivamente), o que não ocorreu para as variáveis percentagem de raízes longas, percentagem de raízes médias, percentagem de raízes curtas, renda líquida e índice de lucratividade do cultivo da cenoura (Tabela 1). A superioridade da testemunha pode ser atribuída à quantidade de material utilizado (40 tha ${ }^{-1}$ de esterco bovino), e, consequentemente, maior fornecimento de nutrientes aplicado. Para a taxa de retorno, a média do fatorial $(4,11)$ foi superior a da testemunha $(2,74)$.

Na produção classificada de raízes, foi observada uma predominância de raízes médias, provenientes tanto dos tratamentos do fatorial $(52,5 \%)$ como do tratamento testemunha $(49,0 \%)$. Resultados semelhantes foram encontrados por diferentes autores (Lopes et al., 2008; Oliveira et al., 2011).

A partir dos resultados obtidos no 
presente trabalho, pode-se constatar que o melhor desempenho agroeconômico do cultivo da cenoura foi obtido com a adição ao solo de 15,6 t ha ${ }^{-1}$ de jitirana. A otimização desse desempenho foi alcançada no tempo de incorporação de 26 dias.

\section{REFERÊNCIAS}

BARBOSA HP. 1997. Tabela de composição de alimentos do estado da Paraíba: Setor agropecuário. João Pessoa: Fundação de Amparo à Pesquisa do Estado da Paraíba. $165 \mathrm{p}$.

BATISTA MAV. 2011. Adubação verde na produtividade, qualidade e rentabilidade de beterraba e rabanete. Mossoró-RN: UFERSA, 123p. (Tese doutorado).

BEZERRA NETO F; GÓES SB; SÁ JR; LINHARES PCF; GÓES GB; MOREIRA JN. 2011. Desempenho agronômico da alface em diferentes quantidades e tempos de decomposição de jitirana verde. Revista Brasileira de Ciências Agrárias 6: 236-242.

BEZERRA NETO F; PORTO VCN; GOMES EG; CECÍLIO FILHO AB; MOREIRA JN. 2012. Assessment of agroeconomic indexes in polycultures of lettuce, rocket and carrot through uni- and multivariate approaches in semi-arid Brazil. Ecological Indicators 14: 11-17.

BRAGA R. 1976. Plantas do nordeste especialmente do Ceará. 3 ed. v. XLII. Fortaleza: ESAM. 1976. 540p.

CORREIA MP. 1984. Dicionário de plantas úteis. v. 4. Mossoró: ESAM.

CARMO FILHO F; ESPÍNOLA SOBRINHO J; MAIA NETO JM. 1991. Dados climatológicos de Mossoró: um município semi-árido nordestino. Mossoró: ESAM. 121p. (Coleção Mossoroense, Série C, 30)

EMPRESA BRASILEIRA DE PESQUISA AGROPECUÁRIA - EMBRAPA. 2006. Centro Nacional de Pesquisa de Solos. Sistema brasileiro de classificação de solos. 2. ed. Rio de Janeiro: Embrapa. 306p.

FERREIRA DF. 2000. Sistema SISVAR para análises estatísticas: Manual de orientação. Lavras: UFLA/DCE. 37p.

FONTANÉTTI A; CARVALHO GJ; GOMES LAA; ALMEIDA K; TEIXEIRA CM. 2006. Adubação verde na produção orgânica de alface americana e repolho. Horticultura Brasileira 24: 146-150.

GÓES SB; BEZERRA NETO F; SÁ JR; LINHARES PCF; GÓES GB; MOREIRA JN. 2011. Productive performance of lettuce at different amounts and times of decomposition of dry scarlet starglory. Revista Ciência Agronômica 42: 1036-1042.

LANA MM; VIEIRA JV. 2000. Fisiologia e manuseio pós-colheita de cenoura. Brasília: EMBRAPA Hortaliças. 15p.

LINHARES PCF. 2009. Vegetação espontânea como adubo verde no desempenho agroeconomico de hortaliças folhosas. Mossoró-RN: UFERSA. 109p. (Tese doutorado).

LINHARES PCF; LIMA GKL; LIBERALINO FILHO J; BEZERRA NETO F; RODRIGUES GSO; PAIVA AP. 2007. Desempenho agroeconômico da rúcula cultivada com diferentes doses de jitirana incorporada. Revista Brasileira de Agroecologia 2: $1487-$ 1490.

LINHARES PCF; PEREIRA MFS; ASSIS JP; BEZERRAAKH. 2012. Quantidades e tempos de decomposição da jitirana no desempenho agronômico do coentro. Ciência Rural 42: 243-248.

LINHARES PCF; SILVA ML; SILVA UL; SILVA
JS; BEZERRA AKH. 2009. Velocidade e tempo de decomposição da jitirana incorporada na cultura do rabanete. Revista Caatinga 22: 213-217.

LOPES WAR; NEGREIROS MZ; TEÓFILO TMS; ALVES SSV; MARTINS CM; NUNES GHS; GRANGEIRO LC. 2008. Produtividade de cultivares de cenoura sob diferentes densidades de plantio. Revista Ceres 55: 482-487.

OLIVEIRA AP; ESPINOLA JEF; ARAUJO JS; COSTA CC. 2001. Produção de raízes de cenoura cultivadas com húmus de minhoca e adubo mineral. Horticultura Brasileira 19: 77-80.

OLIVEIRAMKT; BEZERRANETOF; BARROS JÚNIOR AP; LIMA JSS; MOREIRA, JN. 2011. Desempenho agroeconômico da cenoura adubada com jitirana antes da semeadura. Revista Ciência Agronômica 42: 364-372.

PAULA JÚNIOR TS; VENZON M. 2007. 101 culturas: Manual de tecnologias agrícolas. Belo Horizonte: EPAMIG. 800p.

SILVA ML; BEZERRA NETO F; LINHARES PCF; SÁ JR; LIMA JSS; BARROS JÚNIOR AP. 2011. Produção de beterraba fertilizada com jitirana em diferentes doses e tempos de incorporação ao solo. Revista Brasileira de Engenharia Agrícola e Ambiental 15: 801-809.

SYSTAT SOFTWARE INC. 2002. Table curve $2 D$ and $3 D$. San Jose, CA: MMIV Systat Software Inc.

TORRES JLR; PEREIRA MG; ANDRIOLI I; POLIDORO J; FABIAN AJ. 2005. Decomposição e liberação de nitrogênio de resíduos culturais de plantas de cobertura em um solo de cerrado. Revista Brasileira de Ciência do Solo 29: 609-618.

UFC - UNIVERSIDADE FEDERAL DO CEARA. 1993. Recomendações de adubação e calagem para o Estado do Ceará. Fortaleza: Imprensa Universitária. 247 p. 